\title{
Effects of a novel nutritional formula specially developed for chronic kidney disease patients on protein-restricted diets: a randomized controlled trial
}

\author{
Yoshie Kanazawa ${ }^{1,2}$, Shunsuke Morita ${ }^{3}$, Hirofumi Sonoki ${ }^{3}$ and Toshiyuki Nakao ${ }^{1,4^{*}}$
}

\begin{abstract}
Background: In chronic kidney disease (CKD), the patients on a low-protein diet are considered to be at high risk of protein-energy wasting. Furthermore, a low-protein diet conceivably results in reduced intake of various nutrients. The purpose of this study was to evaluate the effects of a novel high-calorie, low-protein liquid formula containing eicosapentaenoic acid (EPA), docosahexaenoic acid (DHA), lactulose, raffinose, and indigestible dextrin on CKD patients.

Methods: A randomized controlled trial was conducted on the Department of Nephrology at the Tokyo Medical University Hospital, Tokyo, Japan. Forty-three CKD patients prescribed a protein-restricted diet were randomly assigned to a supplement (SUP) or control (CTR) group. All patients received dietary counselling. Only the SUP group was given one or two packs (125 or $250 \mathrm{~mL}$ ) daily of high-calorie, low-protein liquid formula. The intervention period was 16 weeks. Outcome measures of the study were body weight; body mass index (BMI); dietary protein, energy, and salt intake; estimated glomerular filtration rate (eGFR); serum levels of albumin, triglyceride and LDL-cholesterol; plasma fatty acid composition; plasma indoxyl sulfate level; creatinine clearance $(\mathrm{Ccr})$; and urine protein excretion.

Results: There were no differences in energy intake and protein intake between the two groups. Body weight, BMI, plasma eicosapentaenoic acid (EPA), and EPA/arachidonic acid (AA) ratio at 16 weeks were significantly higher in the SUP group than in the CTR group. At 16 weeks, the CTR group showed significant decline in eGFR and significant increase in plasma indoxyl sulfate, whereas the SUP group showed no significant changes from baseline.
\end{abstract}

Conclusions: Supplementation of a novel liquid formula may be beneficial for the management in CKD patients on a protein-restricted diet.

Keywords: Chronic kidney disease, Nutritional supplementation, Low-protein diet, BMI, Clinical trial

\section{Background}

In chronic kidney disease (CKD), a low-protein diet is expected to prevent several clinical complications and delay dialysis initiation [1]. However, it is somewhat difficult to maintain a diet with simultaneously sufficient energy and restricted protein. Furthermore, CKD patients on a low-protein diet are considered to be at high risk of protein-energy wasting for several reasons, one of

\footnotetext{
* Correspondence: t-nakao@tokyo-med.ac.jp

'Organization for Kidney and Metabolic Disease Treatment, 3F, Kubo Bldg., 2-10-12 Yoyogi, Shibuya-ku, Tokyo 151-0053, Japan

${ }^{4}$ Department of Nephrology, Tokyo Medical University, Tokyo, Japan

Full list of author information is available at the end of the article
}

which is insufficient energy intake [2]. Therefore, patients on a low-protein diet often take foods specially developed for CKD such as low-protein rice. In addition, calorie supplement may be useful, and a non-protein calorie supplement has been reported to reduce protein intake and urine protein excretion and increase estimated glomerular filtration rate (eGFR) [3].

A low-protein diet conceivably results in reduced intake of various nutrients in addition to energy. The intake of eicosapentaenoic acid (EPA) and docosahexaenoic acid (DHA) mainly found in fish is also lowered [4]. EPA and DHA are known to have various physiological effects such as lowering inflammation, triglyceride, and 
blood pressure [5]. According to a meta-analysis, intake of n-3 fatty acids significantly reduces urine protein excretion [6]. Thus, EPA and DHA may have renoprotective effects.

Probiotics or prebiotics, such as lactulose, raffinose, and indigestible dextrin, are considered to be another beneficial nutrient for CKD patients. Prebiotics have various beneficial effects on the intestinal environment and metabolism, such as intestinal microflora and glucose homeostasis [7]. Previous research suggested that probiotics and prebiotics reduce p-cresyl sulfate and indoxyl sulfate, which are known as uremic toxins produced by intestinal bacteria [8]. Indoxyl sulfate is considered to be nephrotoxic and promote CKD progression [9]. Therefore, improving intestinal microflora and reducing uremic toxins by prebiotics may be a therapeutic target for CKD patients. Currently, there is an ongoing trial designed to test whether synbiotics that combine both probiotics and prebiotics reduce uremic toxins including indoxyl sulfate in CKD patients [10].

The purpose of this study was to clarify the usefulness of a novel high-calorie, low-protein liquid formula containing EPA, DHA, lactulose, raffinose, and indigestible dextrin for energy supplementation, and to evaluate its effects on eGFR, nutritional status, plasma lipid profile, and plasma indoxyl sulfate as a representative uremic toxin, in patients with chronic renal failure on proteinrestricted diets.

\section{Methods}

\section{Study design}

The study was a prospective, randomized, open-label, controlled clinical trial. This study was conducted at the Tokyo Medical University Hospital in Tokyo, Japan, from May 2010 to May 2012. The study protocol was approved by the ethics committee at the Tokyo Medical University and informed consent was obtained from all participants.

\section{Participants}

All participants were recruited from the Department of Nephrology at the Tokyo Medical University Hospital. The inclusion criteria were CKD stage 4 or 5 (eGFR $<30 \mathrm{~mL} / \mathrm{min} / 1.73 \mathrm{~m}^{2}$ ), prescribed a protein-restricted diet of under $0.8 \mathrm{~g}$ protein per kilogram ideal body weight per day, and 40 to 85 years of age. The exclusion criteria were presence of critical liver diseases, malignant diseases, or infectious diseases; food allergies to milk, soybean, or fish; undergoing hemodialysis or planning for hemodialysis initiation; habitual intake of supplement containing prebiotics; participation in another clinical study; assessed by the principal investigator to be unsuitable to participate in the trial or have difficulties to complete the trial. The participants were randomly assigned to a supplement (SUP) or a control (CTR) group. Randomization was performed using the permuted block method and stratified according to compliance to energy intake and protein intake.

\section{Dietary intervention}

All participants received dietary counselling in addition to medical treatment. If the participants had already received carbon adsorbent (Kremezin (Kureha Corporation, Tokyo, Japan)), probiotics, or ethyl icosapentate (Epadel $^{\mathrm{m}}$ (Mochida Pharmaceutical Co., Ltd., Tokyo, Japan)) before the study, they continued to receive the same agent during the study. Participants in the SUP group took one or two packs of the nutritional formula Renagy bit ${ }^{\text {ma }}$ (Morinaga Milk Industry Co., Ltd., Tokyo, Japan) per day for 16 weeks. One pack of formula $(125 \mathrm{~mL})$ provides $150 \mathrm{kcal}(0.9 \mathrm{~g}$ protein, $31.2 \mathrm{~g}$ carbohydrate, $4.2 \mathrm{~g}$ fat). The formula contains low sodium, potassium, and phosphorus (45, 0-10, and 5-15 mg per pack, respectively). Each pack contains $90 \mathrm{mg}$ EPA, $40 \mathrm{mg}$ DHA, and $4 \mathrm{~g}$ dietary fiber mainly consisting of indigestible dextrin, $1 \mathrm{~g}$ lactulose, $1 \mathrm{~g}$ raffinose, $25 \mathrm{mg} \mathrm{L}-$ carnitine, and also some trace minerals and vitamins. Participants in the CTR group did not take the nutritional formula. Dietary energy and protein prescriptions were expressed as per kilogram ideal body weight (IBW), defined as the weight for body mass index (BMI) of $22 \mathrm{~kg} / \mathrm{m}^{2}$. Energy prescription was $30 \mathrm{kcal} / \mathrm{kg} \mathrm{IBW} /$ day and adjusted by body weight transition. Protein prescription was set at a goal of $0.6-0.8 \mathrm{~g} / \mathrm{kg} \mathrm{IBW} /$ day. The SUP group recorded their intake of the nutritional formula on their designated chart every day throughout this study. Compliance (\%) for nutritional formula intake was calculated from the number of packs determined by patient's record and dietary interview.

\section{Assessments and parameters}

Body weight measurement, blood sampling, and 24-h urine collection were conducted at 0,8 , and 16 weeks. Plasma fatty acid composition and body composition were measured at 0 and 16 weeks. Outcome measures of the study were body weight, BMI, protein intake, energy intake, salt intake, eGFR, serum albumin, serum triglyceride, serum LDL-cholesterol, plasma fatty acid composition, plasma indoxyl sulfate, creatinine clearance $(\mathrm{Ccr})$, and urine protein excretion. Serum total protein, prealbumin, total cholesterol, HDL cholesterol, creatinine, C-reactive protein, and blood urea nitrogen (BUN) were also measured. The eGFR was calculated by the three-variable Japanese equation formerly reported [11]. Energy intake was estimated from the dietary interview and dietary records for four or more days at each point using the standard tables of food composition in Japan. Protein intake was calculated by the Maroni formula 
[12]. Sodium chloride equivalent as salt intake was calculated from urine sodium excretion. Ccr was calculated from serum creatinine, urine creatinine, and urine volume. Energy intake and protein intake were expressed as per IBW. Body composition was measured by InBody 2.0 (Biospace Co., Ltd., Seoul, Korea). Plasma fatty acid composition was measured by gas chromatography. Plasma indoxyl sulfate was measured by high-performance liquid chromatography.

\section{Statistical analysis}

Participants with low nutritional formula compliance of lower than $80 \%$ were excluded from the analysis. Numerical variables were expressed as mean \pm standard deviation (SD). For the baseline characteristics, comparisons of numerical data were performed using Student's $t$ test and comparisons of categorical data were performed using Fisher's exact test. Analysis of covariance was used to evaluate the intervention effect in numerical variables with the baseline value as a covariate. The changes from the baseline were evaluated using paired Student's $t$ test. Logarithmic normalized values of indoxyl sulfate concentrations were used [13]. Differences with $P<0.05$ (two-sided) were considered statistically significant. All calculations were conducted using SAS version 9.2 (SAS Institute, Cary, NC, USA).

\section{Results}

\section{Baseline characteristics}

Flow diagram of participants is shown in Fig. 1. Of 61 patients recruited, 43 were randomly assigned to the SUP group (21 patients) or the CTR group (22 patients). Two participants in the SUP group discontinued the study before the nutritional formula intake because of complication. One participant in the CTR group dropped out after 6 weeks of the study (laboratory data until 8 weeks) because of dialysis initiation. One participant in the SUP group was excluded from analysis due to low compliance (below $80 \%$ ). Eventually, analyses were conducted in 18 participants in the SUP group and 22 in the CTR group. Baseline characteristics are shown in Table 1. With the exception of BUN, no significant differences between two groups were observed.

\section{Dietary intake}

Energy intake and protein intake are shown in Table 2. There were no significant differences between two groups in energy intake and protein intake. There were no significant changes from the baseline in energy intake (16-week intake versus baseline intake in the SUP group, $P=0.07)$ and protein intake. Energy intake from the nutritional formula in the SUP group was $180 \pm 60 \mathrm{kcal} /$ day $(1.2 \pm 0.4 \mathrm{packs} /$ day $)$. Although the rate of energy intake for a prescribed amount in the SUP group increased from $93 \pm 13 \%$ at baseline to $98 \pm 14 \%$ at 16 weeks, there was no significant difference $(P=0.09)$. The rate of energy intake for a prescribed amount in the CTR group also increased from $90 \pm 15 \%$ at baseline to $94 \pm 14 \%$ at 16 weeks, also with no significant difference. Although the formula contains indigestible dextrin, lactulose, and raffinose, diarrhea was not observed in this study.

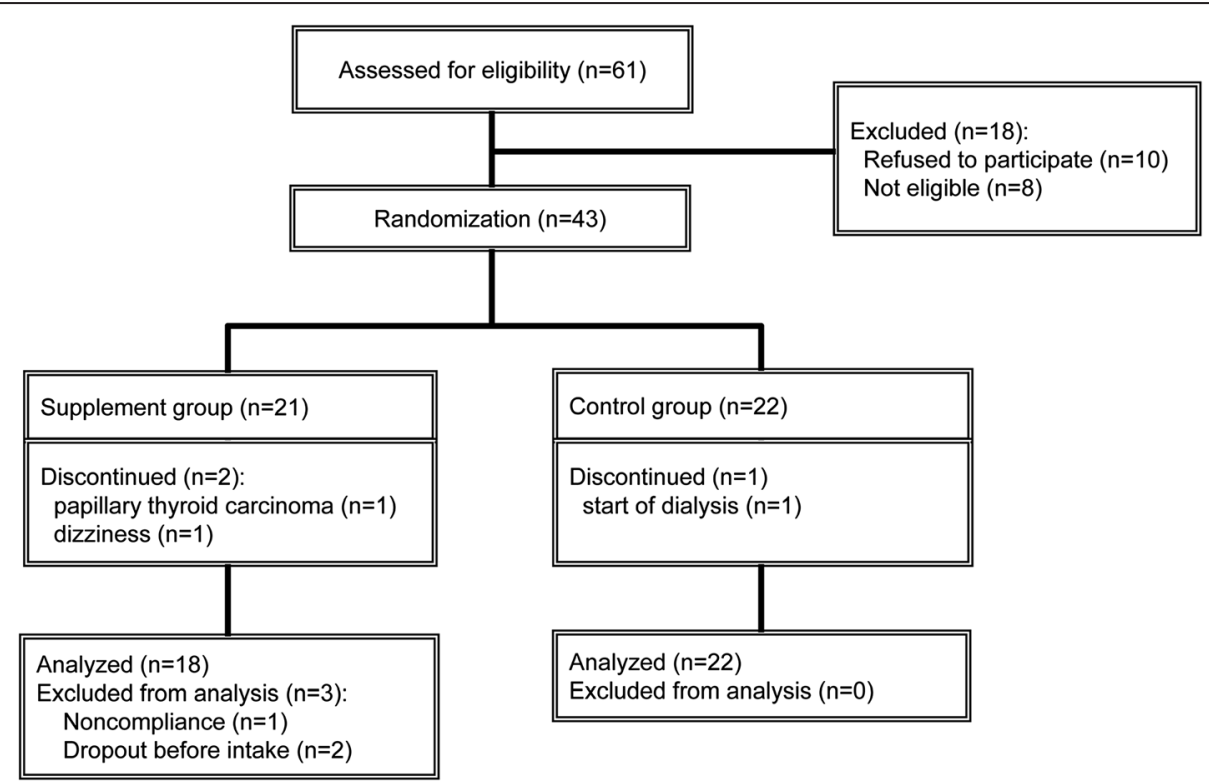

Fig. 1 Flow diagram of participants 
Table 1 Baseline characteristics

\begin{tabular}{|c|c|c|c|}
\hline \multirow[t]{2}{*}{ Variable } & \multirow{2}{*}{$\begin{array}{l}\text { SUP } \\
n=18\end{array}$} & \multirow{2}{*}{$\begin{array}{l}\text { CTR } \\
n=22\end{array}$} & \multirow[t]{2}{*}{$P$ value } \\
\hline & & & \\
\hline Age (year) & $65.9 \pm 9.7$ & $68.3 \pm 8.7$ & 0.43 \\
\hline Male to female & $12: 6$ & $17: 5$ & 0.50 \\
\hline DM to non-DM & $4: 14$ & $9: 13$ & 0.31 \\
\hline ARB/ACEI (use to non-use) & $17: 1$ & $18: 4$ & 0.36 \\
\hline Body weight (kg) & $65.6 \pm 6.6$ & $66.0 \pm 8.9$ & 0.86 \\
\hline $\mathrm{BMI}\left(\mathrm{kg} / \mathrm{m}^{2}\right)$ & $25.0 \pm 1.8$ & $24.6 \pm 2.9$ & 0.66 \\
\hline$\% \mathrm{IBW}$ & $114 \pm 8$ & $112 \pm 13$ & 0.66 \\
\hline Energy (kcal/kg IBW/day) & $29 \pm 4$ & $28 \pm 5$ & 0.49 \\
\hline Protein (g/kg IBW/day) & $0.75 \pm 0.18$ & $0.78 \pm 0.19$ & 0.67 \\
\hline BUN (mg/dL) & $37.0 \pm 12.3$ & $49.7 \pm 21.6$ & 0.03 \\
\hline Creatinine (mg/dL) & $3.9 \pm 2.0$ & $4.6 \pm 3.4$ & 0.44 \\
\hline $\mathrm{eGFR}\left(\mathrm{mL} / \mathrm{min} / 1.73 \mathrm{~m}^{2}\right)$ & $15.4 \pm 7.1$ & $13.6 \pm 6.8$ & 0.43 \\
\hline Indoxyl sulfate (log $\mu \mathrm{g} / \mathrm{mL})(\mu \mathrm{g} / \mathrm{mL})$ & $0.71 \pm 0.49(5.2)$ & $0.82 \pm 0.29(6.3)$ & 0.36 \\
\hline Urine protein excretion (g/day) & $0.9 \pm 0.9$ & $2.3 \pm 3.9$ & 0.15 \\
\hline $\mathrm{CRP}(\mathrm{mg} / \mathrm{dL})$ & $0.04 \pm 0.04$ & $0.11 \pm 0.15$ & 0.10 \\
\hline
\end{tabular}

Values inside parenthesis are the median

SUP supplement group, CTR control group (no supplement), DM diabetes mellitus, $A R B$ angiotensin II receptor blocker, $A C E I$ angiotensin-converting enzyme inhibitor, $B M I$ body mass index, IBW ideal body weight, $B U N$ blood urea nitrogen, eGFR estimated glomerular filtration rate, $C R P C$-reactive protein

\section{Body composition}

Body weight and body composition are shown in Table 2. Body weight, BMI, and \%IBW were significantly higher in the SUP group than in the CTR group at 16 weeks. Body weight, BMI, and \%IBW in the SUP group increased significantly from baseline. The intake of nutritional formula correlated with change in body weight $(r=0.33, P<0.05)$.

\section{Laboratory findings}

Biochemical parameters and urine protein excretion are shown in Table 3. Although BUN was significantly higher in the SUP group than in the CTR group at 8 weeks, there were no significant differences between two groups in all biochemical parameters and urine protein excretion at 16 weeks. There were no significant changes from baseline to 16 weeks in both groups.

Table 2 Nutrient intake, body weight, and body composition

\begin{tabular}{|c|c|c|c|c|c|c|}
\hline \multirow[b]{2}{*}{ Variable } & \multicolumn{3}{|l|}{ SUP } & \multicolumn{3}{|l|}{ CTR } \\
\hline & 0 week & 8 weeks & 16 weeks & 0 week & 8 weeks & 16 weeks \\
\hline Energy (kcal/kg IBW/day) & $29 \pm 4$ & $30 \pm 3$ & $30 \pm 4$ & $28 \pm 5$ & $29 \pm 5$ & $29 \pm 5$ \\
\hline Protein (g/kg IBW/day) & $0.76 \pm 0.18$ & $0.76 \pm 0.20$ & $0.74 \pm 0.19$ & $0.78 \pm 0.19$ & $0.77 \pm 0.26$ & $0.78 \pm 0.25$ \\
\hline Salt (g/day) & $7.2 \pm 2.3$ & $7.3 \pm 2.3$ & $7.3 \pm 2.1$ & $8.2 \pm 3.0$ & $8.6 \pm 3.8$ & $7.7 \pm 3.5$ \\
\hline BW (kg) & $65.6 \pm 6.6$ & $66.2 \pm 6.4^{* *}$ & $66.5 \pm 6.5^{* * * * *}$ & $66.0 \pm 8.9$ & $66.2 \pm 8.6$ & $65.7 \pm 8.7$ \\
\hline $\mathrm{BMI}\left(\mathrm{kg} / \mathrm{m}^{2}\right)$ & $25.0 \pm 1.8$ & $25.2 \pm 1.9^{* *}$ & $25.4 \pm 2.0^{* * * *}$ & $24.6 \pm 2.9$ & $24.7 \pm 2.9$ & $24.3 \pm 2.5$ \\
\hline$\% \mathrm{BWW}$ & $114 \pm 8$ & $115 \pm 9^{* *}$ & $115 \pm 9^{* * * * *}$ & $112 \pm 13$ & $112 \pm 13$ & $110 \pm 11$ \\
\hline LBM (kg) & $47.5 \pm 7.4$ & - & $49.8 \pm 10.5$ & $48.9 \pm 7.8$ & - & $48.7 \pm 7.6$ \\
\hline $\mathrm{BP}(\mathrm{kg})$ & $12.0 \pm 1.9$ & - & $12.6 \pm 2.7$ & $12.3 \pm 2.0$ & - & $12.3 \pm 1.9$ \\
\hline ICW (kg) & $21.6 \pm 2.6$ & - & $22.4 \pm 4.2$ & $21.8 \pm 3.5$ & - & $21.8 \pm 3.5$ \\
\hline $\mathrm{ECW}(\mathrm{kg})$ & $11.3 \pm 1.7$ & - & $12.1 \pm 3.4$ & $12.1 \pm 2.2$ & - & $12.0 \pm 2.0$ \\
\hline Mineral (kg) & $2.6 \pm 0.3$ & - & $2.7 \pm 0.5$ & $2.7 \pm 0.3$ & - & $2.7 \pm 0.3$ \\
\hline BFM (kg) & $17.1 \pm 5.0$ & - & $15.7 \pm 7.8$ & $16.1 \pm 5.2$ & - & $15.9 \pm 4.7$ \\
\hline
\end{tabular}

SUP supplement group, CTR control group (no supplement), Salt intake sodium chloride equivalent, $B W$ body weight, $B M I$ body mass index, IBW ideal body weight, $B P$ body protein, $L B M$ lean body mass, $I C W$ intracellular water, $E C W$ extracellular water, $B F M$ body fat mass

${ }^{*} P<0.05$ versus $C T R,{ }^{* *} P<0.05,{ }^{* * *} P<0.01$ versus 0 week 
Table 3 Laboratory test

\begin{tabular}{|c|c|c|c|c|c|c|}
\hline \multirow[b]{2}{*}{ Variable } & \multicolumn{3}{|l|}{ SUP } & \multicolumn{3}{|l|}{ CTR } \\
\hline & 0 week & 8 weeks & 16 weeks & 0 week & 8 weeks & 16 weeks \\
\hline Total protein (g/dL) & $7.0 \pm 0.4$ & $6.9 \pm 0.3$ & $6.9 \pm 0.4$ & $6.8 \pm 0.7$ & $6.8 \pm 0.7$ & $6.9 \pm 0.6$ \\
\hline Albumin (g/dL) & $4.1 \pm 0.3$ & $4.0 \pm 0.3$ & $4.1 \pm 0.3$ & $3.9 \pm 0.6$ & $3.9 \pm 0.6$ & $4.0 \pm 0.4$ \\
\hline Prealbumin (mg/dL) & $32.8 \pm 7.5$ & $33.2 \pm 7.7$ & $33.2 \pm 7.25$ & $31.0 \pm 6.6$ & $30.5 \pm 5.6$ & $31.4 \pm 6.4$ \\
\hline Triglyceride (mg/dL) & $143 \pm 79$ & $148 \pm 93$ & $158 \pm 76$ & $142 \pm 98$ & $147 \pm 99$ & $156 \pm 89$ \\
\hline T-Cho (mg/dL) & $179 \pm 36$ & $177 \pm 33$ & $179 \pm 32$ & $173 \pm 27$ & $173 \pm 29$ & $173 \pm 24$ \\
\hline LDL-Cho (mg/dL) & $95.4 \pm 28.7$ & $91.8 \pm 24.8$ & $94.7 \pm 25.0$ & $88.5 \pm 18.7$ & $89.6 \pm 18.6$ & $89.1 \pm 22.9$ \\
\hline HDL-Cho (mg/dL) & $47.6 \pm 17.6$ & $46.6 \pm 17.4$ & $45.9 \pm 16.2$ & $46.9 \pm 15.0$ & $46.6 \pm 15.7$ & $45.4 \pm 15.1$ \\
\hline Creatinine $(\mathrm{mg} / \mathrm{dL})$ & $3.9 \pm 2.0$ & $4.1 \pm 2.5$ & $4.1 \pm 2.5$ & $4.6 \pm 3.4$ & $5.0 \pm 4.4$ & $5.0 \pm 4.2$ \\
\hline BUN (mg/dL) & $37.0 \pm 12.3$ & $39.5 \pm 18.0^{*}$ & $38.5 \pm 16.0$ & $49.7 \pm 21.6$ & $47.5 \pm 26.6$ & $50.3 \pm 16.4$ \\
\hline CRP $(\mathrm{mg} / \mathrm{dL})$ & $0.04 \pm 0.04$ & $0.06 \pm 0.05$ & $0.07 \pm 0.08$ & $0.11 \pm 0.15$ & $0.22 \pm 0.61$ & $0.06 \pm 0.06$ \\
\hline $\operatorname{Ccr}(\mathrm{mL} / \mathrm{min})$ & $22.7 \pm 11.7$ & $23.8 \pm 12.1$ & $21.9 \pm 11.6$ & $20.0 \pm 10.7$ & $21.1 \pm 10.7$ & $19.3 \pm 9.9$ \\
\hline UPE (g/day) & $0.9 \pm 0.9$ & $1.0 \pm 0.8$ & $1.1 \pm 1.2$ & $2.3 \pm 3.9$ & $1.9 \pm 3.9$ & $1.5 \pm 2.8$ \\
\hline
\end{tabular}

SUP supplement group, CTR control group (no supplement), T-Cho total cholesterol, LDL-Cho low-density lipoprotein cholesterol, HDL-Cho high-density lipoprotein cholesterol, BUN blood urea nitrogen, CRP C-reactive protein, $C C r$ creatinine clearance, UPE urine protein excretion

${ }^{*} P<0.05$ versus $C T R$

Although hemoglobin A1c was not shown in Table 3, the significant difference was not observed in diabetic patients (SUP: $n=4,6.3 \pm 0.2$ to $6.2 \pm 0.3$, CTR: $n=9$, $6.4 \pm 0.9$ to $5.9 \pm 0.5,0$ to 16 weeks).

\section{Plasma fatty acid composition}

Plasma fatty acid composition is shown in Table 4. Plasma EPA, $\alpha$-linolenic acid, EPA/arachidonic acid (AA) ratio, and $n-3 / n-6$ ratio were significantly higher in the SUP group than in the CTR group. In the SUP group, EPA, EPA/AA ratio, and n-3/n-6 ratio increased significantly from baseline. The intake of nutritional formula correlated with change in EPA/AA ratio $(r=0.46$, $P<0.01)$. EPA and EPA/AA ratio were significantly higher in the SUP group than in the CTR group. In the
SUP group, EPA and EPA/AA ratio increased significantly from baseline.

In a subgroup analysis excluding participants receiving ethyl icosapentate (SUP group: $n=15$, CTR group: $n=16)$, EPA and EPA/AA ratio were significantly higher in the SUP group than in the CTR group. In the SUP group, EPA and EPA/AA increased significantly from baseline.

\section{Renal function and plasma indoxyl sulfate}

Estimated GFR in the CTR group decreased significantly by $1.2 \pm 2.6 \mathrm{~mL} / \mathrm{min} / 1.73 \mathrm{~m}^{2}$ at 16 weeks, but eGFR in the SUP group changed slightly by $0.1 \pm 3.5 \mathrm{~mL} / \mathrm{min} /$ $1.73 \mathrm{~m}^{2}$ and this change was not significant (Fig. 2a). In addition, the changes of $\mathrm{Ccr}$ significantly correlated with

Table 4 Plasma fatty acid composition in all subjects (A) and in the subgroup not prescribed EPA (B)

\begin{tabular}{|c|c|c|c|c|}
\hline \multirow[b]{2}{*}{ Variable } & \multicolumn{2}{|l|}{ SUP } & \multicolumn{2}{|l|}{ CTR } \\
\hline & 0 week & 16 weeks & O week & 16 weeks \\
\hline \multicolumn{5}{|l|}{ A. All subjects } \\
\hline $\mathrm{EPA}(\mu \mathrm{g} / \mathrm{mL})$ & $62.5 \pm 37.0$ & $85.8 \pm 50.0^{* * * *}$ & $87.7 \pm 76.9$ & $87.0 \pm 77.2$ \\
\hline $\mathrm{DHA}(\mu \mathrm{g} / \mathrm{mL})$ & $124.1 \pm 63.8$ & $149.9 \pm 95.6$ & $116.7 \pm 52.9$ & $118.4 \pm 39.0$ \\
\hline ARA $(\mu \mathrm{g} / \mathrm{mL})$ & $142.6 \pm 45.5$ & $142.0 \pm 47.3$ & $150.7 \pm 57.8$ & $149.4 \pm 44.0$ \\
\hline a-Linolenic acid $(\mu \mathrm{g} / \mathrm{mL})$ & $33.3 \pm 17.2$ & $39.0 \pm 16.9^{*}$ & $31.6 \pm 23.4$ & $29.2 \pm 12.9$ \\
\hline$n-3 / n-6$ ratio & $0.24 \pm 0.09$ & $0.30 \pm 0.11^{* * * *}$ & $0.28 \pm 0.17$ & $0.26 \pm 0.12$ \\
\hline EPA/AA ratio & $0.47 \pm 0.34$ & $0.67 \pm 0.51^{* * * * *}$ & $0.72 \pm 0.81$ & $0.65 \pm 0.62$ \\
\hline \multicolumn{5}{|c|}{ B. Subgroup not prescribed EPA } \\
\hline $\mathrm{EPA}(\mu \mathrm{g} / \mathrm{mL})$ & $55.4 \pm 34.4$ & $75.6 \pm 47.7^{* * * *}$ & $48.4 \pm 27.3$ & $43.7 \pm 21.9$ \\
\hline EPA/AA ratio & $0.36 \pm 0.19$ & $0.51 \pm 0.26^{* * * *}$ & $0.31 \pm 0.19$ & $0.31 \pm 0.20$ \\
\hline
\end{tabular}

SUP supplement group, CTR control group (no supplement), EPA eicosapentaenoic acid, DHA docosahexaenoic acid, ARA arachidonic acid, EPA/AA eicosapentaenoic acid/arachidonic acid

${ }^{*} P<0.05$ versus $C T R,{ }^{* * *} P<0.01$ versus 0 week 

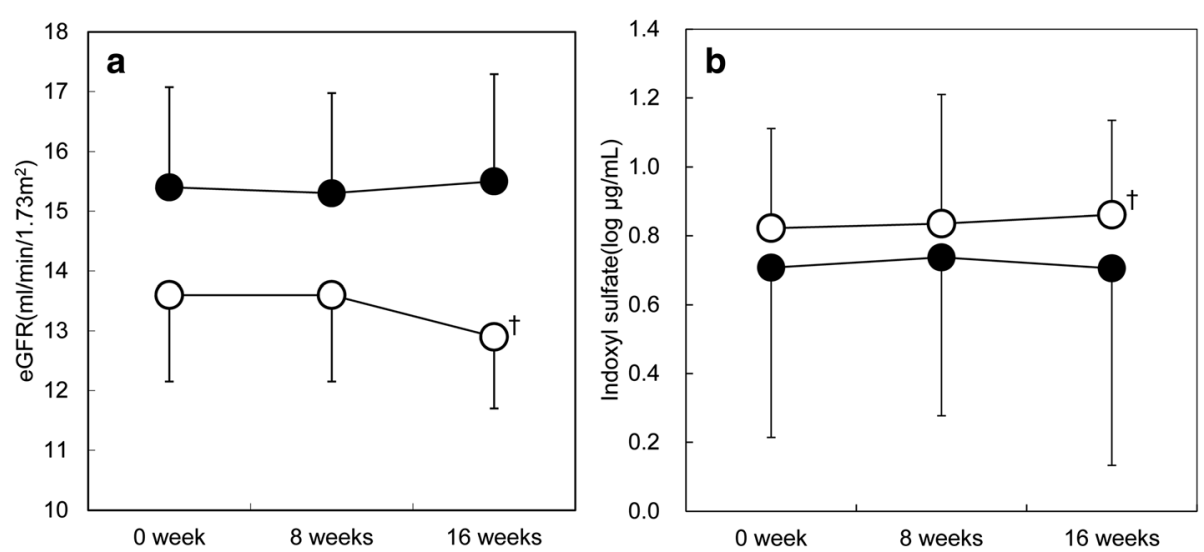

Fig. 2 Effect of oral supplementation on eGFR (a) and plasma indoxyl sulfate (b). eGFR estimated glomerular filtration rate. Filled circles indicate the SUP group. Open circles indicate the CTR group. ${ }^{\dagger} P<0.05$ versus 0 week

the changes of eGFR $(r=0.69, P<0.01)$. The CTR group showed a significant increase in plasma indoxyl sulfate at 16 weeks, whereas the SUP group showed no significant changes from baseline (Fig. 2b).

\section{Discussion}

In this study, we evaluated the effects of energy and nutrient supplementation using a high-calorie, low-protein liquid formula containing various nutrients on patients with CKD stage 4 and 5 before dialysis initiation.

The body weight in the SUP group was significantly higher than that in the CTR group and significantly increased from baseline. Moreover, the amount of intake of the nutritional formula correlated with change in body weight. Although energy intake was not significantly changed, that in the SUP group tended to increase from baseline $(P=0.07)$. This might mean that the nutritional formula partially increased energy intake. Huang et al. [14] reported that energy intake in over one half of CKD patients was less than $90 \%$ of the recommended levels. In the present study, because all participants had received dietary counselling from more than 1 month before the study and had already taken various types of low-protein foods and calorie supplements before this study, the rate of energy intake for a prescribed amount at baseline was higher than $90 \%$, and considered to be relatively sufficient. For patients whose energy intake was over the prescribed amount, they were advised during dietary counselling to replace the part of their usual foods with the nutritional formula to adjust energy intake to the prescribed level. Under such conditions, the rate of energy intake in the SUP group increased from 93 to $98 \%(P=0.09)$. Therefore, using the nutritional formula together with other low-protein foods may be useful to improve the compliance to energy intake. However, protein intake did not differ significantly between two groups. Moreover, protein intake did not change from baseline in both groups and was similarly maintained between 0.6 and $0.8 \mathrm{~g} / \mathrm{kg} \mathrm{IBW} /$ day. In addition, it was considered that the formula had high receptivity and clinical adaptability because of its high compliance. Taken together, the nutritional formula is considered to be as useful as other low-protein foods for protein control.

In addition, the formula provides various nutrients that are supposed to be beneficial for CKD patients. Among them, we focused on $n-3$ polyunsaturated fatty acids (EPA, DHA) and prebiotics (lactulose, raffinose, indigestible dextrin). In the present study, we observed significant increases in plasma EPA and EPA/AA ratio in the SUP group. EPA and DHA are converted from $\alpha-$ linolenic acid. However, due to the limited converting activity, intake from diet is considered necessary. Although EPA and DHA have various physiological effects, there is insufficient evidence to set the dietary requirements for those effects. The minimum requirement of EPA and DHA for healthy adults has been suggested to be $250-500 \mathrm{mg}$ based on the risk for cardiovascular disease (CVD) [15]. Although EPA and DHA intake is estimated to be higher in Japan than in many European countries and the USA [16], inadequate intake accompanying a low-protein diet is a concern. The intake of EPA and DHA during low-protein diet has been reported to be $113 \pm 153 \mathrm{mg}$ and $156 \pm 178 \mathrm{mg}$, respectively [4]. In the present study, baseline EPA/AA ratio in the subjects not prescribed EPA was low, because Yanagisawa et al. [17] reported that serum EPA/AA ratio of healthy Japanese elderly (aged over 65 years) living in an urban area was $0.68 \pm 0.22$. Therefore, supplementation of the nutritional formula containing $130 \mathrm{mg}$ of EPA and DHA per pack may be useful for CKD patients on a low-protein diet to prevent CVD events. 
Plasma indoxyl sulfate increased in the CTR group, but was not changed in the SUP group. Production of indole, a precursor of indoxyl sulfate, by intestinal bacteria such as Escherichia coli is considered to alter under various conditions $[18,19]$. Lactulose and raffinose are known to stimulate growth of Bifidobacteria in the gut [20]. In addition, lactulose has been reported to decrease fecal $\mathrm{pH}$ and indole [21]. In this study, protein intake was not significantly different between SUP and CTR groups. On the other hand, prebiotics including indigestible dextrin in the SUP group presumably provide carbohydrate as energy source to intestinal bacteria. Regarding dietary fiber, it is considered to be insufficient for most people in general. In CKD patients, this trend may be more prominent in the cases of lowering vegetable intake along with potassium control. Although it remains unclear whether intestinal microflora, carbohydrate, $\mathrm{pH}$, or other factors were mainly involved in the increase in plasma indoxyl sulfate in the CTR group, the lactulose, raffinose, and indigestible dextrin contained in the nutritional formula may be beneficial to maintain the intestinal environment for CKD patients.

Estimated GFR declined in the CTR group, but was unchanged in the SUP group. Whether supplementation of nutrients by the present formula prevents the decline of eGFR is of crucial interest. In this study, no significant difference in urinary protein excretion was observed. The intake of EPA and DHA was lower than that reported in the meta-analysis [6]. However, the increase in plasma EPA/ AA ratio may have renoprotective effects. The decline of renal function is known to induce compensatory hyperfiltration [22]. Prostaglandins have been associated with renal hemodynamic regulation in response to protein feeding [23]. Cyclooxygenase-2 inhibitor inhibits hyperfiltration by high protein intake in an animal model [24]. It is possible that EPA competes with AA to influence eGFR via cyclooxygenase-2. Another factor such as blood pressure might be involved in renal function. EPA and DHA are known to lower blood pressure [5]. However, it was uncertain whether EPA and DHA were effective in high blood pressure because most patients received antihypertensive drugs including ARB/ACEI treatment under usual therapy.

The increase in plasma indoxyl sulfate may affect eGFR in the CTR group. Indoxyl sulfate is considered to be nephrotoxic. A carbon adsorbent known to reduce serum indoxyl sulfate prevented CKD progression in a small study [25]. However, in the recent Evaluating Prevention of Progression in CKD (EPPIC) study, the carbon adsorbent was not effective in preventing CKD progression [26]. Further study is required to confirm whether indoxyl sulfate is related to kidney dysfunction and CKD progression.

Energy intake may also influence eGFR. Compared to adequate or high energy intake, low energy intake was related to decreased GFR [14]. In this study, whether increase in the rate of energy intake in the SUP group, improved eGFR remains unclear, because the rate of energy intake at baseline was already relatively high and \%IBW was greater than $100 \%$ throughout the study. The nutritional formula provides various nutrients. Therefore, it is difficult to confirm a direct association between the outcomes and each nutrient. Preservation of eGFR in the SUP group is probably a complex effect of many nutrients in this formula.

There are some limitations in this study. The number of participants who could be evaluated for energy supplementation by this formula was small, because many patients already had sufficient energy intake at screening. The study period may also be insufficient to evaluate the effect of the formula on eGFR. In the Modification of Diet in Renal Disease (MDRD) study 2 with mean follow-up of 2.2 years, the participants had similar GFR to that in the present study and the overall decline of GFR was $4.0 \mathrm{~mL} /$ $\mathrm{min} /$ year [27]. The decline in eGFR in the CTR group (decline of $1.2 \mathrm{~mL} / \mathrm{min} / 1.73 \mathrm{~m}^{2}$ during 16 weeks) was considered to be similar to that in MDRD study, whereas eGFR in the SUP group hardly changed. The short study period in the present study may account for no significant difference in eGFR detected between two groups. Much longer studies are needed to ascertain whether energy and nutrient supplementation is effective to prevent the decline of eGFR and delay dialysis initiation.

\section{Conclusions}

The body weight, BMI, plasma EPA, and EPA/AA were higher in the SUP group than in the CTR group. The decline of eGFR and increase of plasma indoxyl sulfate from baseline were not observed in the SUP group. Highcalorie, low-protein liquid formula containing EPA, DHA, lactulose, raffinose, and indigestible dextrin was considered to be useful for nutritional management in patients with chronic renal failure on protein-restricted diets.

\section{Competing interests}

Shunsuke Morita and Hirofumi Sonoki are employed by Morinaga Milk Industry Co., Ltd.

Yoshie Kanazawa and Toshiyuki Nakao had no competing interests to declare in relation to this article.

\section{Authors' contributions \\ YK designed the study, collected clinical data, and wrote the manuscript. SM designed the study and performed data analysis. HS designed the study. TN designed the study, collected clinical data, performed data analysis, and wrote the manuscript. All authors read and approved the final manuscript.}

\section{Acknowledgements}

We thank Hiroshi Matsumoto, Tomonari Okada, Yume Nagaoka, Toshikazu Wada, Hideaki Iwasawa, Yoshiko Kimura, Satoko Yamamoto and the staff of the Department of Nephrology, Tokyo Medical University, and Hiromi Yamada, Kumiko Yamamoto of Clinical Trial Management Section, Tokyo Medical University Hospital for great assistance on this study. Morinaga Milk Industry Co., Ltd. supported us with funding and provided the nutritional formula. 


\section{Author details}

Organization for Kidney and Metabolic Disease Treatment, 3F, Kubo Bldg. 2-10-12 Yoyogi, Shibuya-ku, Tokyo 151-0053, Japan. ²Department of Health and Nutrition Faculty of Contemporary Human Life Science, Tokyo Kasei Gakuin University, Tokyo, Japan. ${ }^{3}$ Nutritional Science Institute, Morinaga Milk Industry Co., Ltd., Zama, Japan. ${ }^{4}$ Department of Nephrology, Tokyo Medical University, Tokyo, Japan.

\section{Received: 25 November 2015 Accepted: 1 March 2016}

\section{Published online: 16 May 2016}

\section{References}

1. Walser M, Mitch WE, Maroni BJ, Kopple JD. Should protein intake be restricted in predialysis patients? Kidney Int. 1999;55(3):771-7.

2. Kovesdy CP, Kopple JD, Kalantar-Zadeh K. Management of protein-energy wasting in non-dialysis-dependent chronic kidney disease: reconciling low protein intake with nutritional therapy. Am J Clin Nutr. 2013;97(6):1163-77.

3. Wu HL, Sung JM, Kao MD, Wang MC, Tseng CC, Chen ST. Nonprotein calorie supplement improves adherence to low-protein diet and exerts beneficial responses on renal function in chronic kidney disease. J Ren Nutr. 2013;23(4):271-6

4. Kanazawa $Y$, Nakao T, Matsumoto H, Okada T, Hidaka H, Han M, et al. Evaluation of fat nutrition in the energy intake on low protein diets for patients with chronic renal failure. [Article in Japanese]. Nihon Jinzo Gakkai Shi. 1999:41(4):436-41.

5. Friedman AN. Omega-3 fatty acid supplementation in advanced kidney disease. Semin Dial. 2010;23(4):396-400.

6. Miller 3rd ER, Juraschek SP, Appel LJ, Madala M, Anderson CA, Bleys J, et al. The effect of n-3 long-chain polyunsaturated fatty acid supplementation on urine protein excretion and kidney function: meta-analysis of clinical trials. Am J Clin Nutr. 2009;89(6):1937-45.

7. Roberfroid M, Gibson GR, Hoyles L, McCartney AL, Rastall R, Rowland I, et al. Prebiotic effects: metabolic and health benefits. Br J Nutr. 2010;104 Suppl 2: S1-63.

8. Rossi M, Klein K, Johnson DW, Campbell KL. Pre-, pro-, and synbiotics: do they have a role in reducing uremic toxins? A systematic review and metaanalysis. Int J Nephrol. 2012;2012:673631.

9. Meijers BK, Evenepoel P. The gut-kidney axis: indoxyl sulfate, p-cresyl sulfate and CKD progression. Nephrol Dial Transplant. 2011:26(3):759-61.

10. Rossi M, Johnson DW, Morrison M, Pascoe E, Coombes JS, Forbes JM, et al. SYNbiotics Easing Renal failure by improving Gut microbiologY (SYNERGY): a protocol of placebo-controlled randomised cross-over trial. BMC Nephrol. 2014;15:106.

11. Matsuo S, Imai E, Horio M, Yasuda Y, Tomita K, Nitta K, et al. Collaborators developing the Japanese equation for estimated GFR: revised equations for estimated GFR from serum creatinine in Japan. Am J Kidney Dis. 2009;53(6): 982-92.

12. Maroni BJ, Steinman TI, Mitch WE. A method for estimating nitrogen intake of patients with chronic renal failure. Kidney Int. 1985;27(1):58-65.

13. Barreto FC, Barreto DV, Liabeuf S, Meert N, Glorieux G, Temmar M, et al. European Uremic Toxin Work Group (EUTox): serum indoxyl sulfate is associated with vascular disease and mortality in chronic kidney disease patients. Clin J Am Soc Nephrol. 2009;4(10):1551-8.

14. Huang MC, Chen ME, Hung $\mathrm{HC}$, Chen $\mathrm{HC}$, Chang WT, Lee $\mathrm{CH}$, et al. Inadequate energy and excess protein intakes may be associated with worsening renal function in chronic kidney disease. J Ren Nutr. 2008;18(2): 187-94.

15. Flock MR, Harris WS, Kris-Etherton PM. Long-chain omega-3 fatty acids: time to establish a dietary reference intake. Nutr Rev. 2013;71(10):692-707.

16. Hibbeln JR, Nieminen LR, Blasbalg TL, Riggs JA, Lands WE. Healthy intakes of n-3 and n-6 fatty acids: estimations considering worldwide diversity. Am J Clin Nutr. 2006;83(6(Suppl)):1483S-93S.

17. Yanagisawa N, Shimada K, Miyazaki T, Kume A, Kitamura Y, Ichikawa R, et al. Polyunsaturated fatty acid levels of serum and red blood cells in apparently healthy Japanese subjects living in an urban area. J Atheroscler Thromb. 2010;17(3):285-94

18. Lee JH, Lee J. Indole as an intercellular signal in microbial communities. FEMS Microbiol Rev. 2010;34(4):426-44.

19. Han $\mathrm{TH}$, Lee $\mathrm{JH}$, Cho MH, Wood TK, Lee J. Environmental factors affecting indole production in Escherichia coli. Res Microbiol. 2011;162(2):108-16.
20. Mitsuoka T. Development of functional foods. Biosci Microbiota Food Health. 2014;33(3):117-28.

21. Terada A, Hara H, Kataoka M, Mitsuoka T. Effect of lactulose on the composition and metabolic activity of the human faecal flora. Microb Ecol Health Dis. 1992;24(5):43-50.

22. Brenner BM. Hemodynamically mediated glomerular injury and the progressive nature of kidney disease. Kidney Int. 1983;23(4):647-55.

23. Woods LL. Mechanisms of renal hemodynamic regulation in response to protein feeding. Kidney Int. 1993:44(4):659-75.

24. Yao B, Xu J, Qi Z, Harris RC, Zhang MZ. Role of renal cortical cyclooxygenase-2 expression in hyperfiltration in rats with high-protein intake. Am J Physiol Renal Physiol. 2006;291(2):F368-74.

25. Schulman G, Vanholder R, Niwa T. AST-120 for the management of progression of chronic kidney disease. Int J Nephrol Renovasc Dis. 2014;7:49-56.

26. Schulman G, Berl T, Beck GJ, Remuzzi G, Ritz E, Arita K, et al. Randomized placebo-controlled EPPIC trials of AST-120 in CKD. J Am Soc Nephrol. 2014; 26(7):1732-46.

27. Klahr S, Levey AS, Beck GJ, Caggiula AW, Hunsicker L, Kusek JW, et al. The effects of dietary protein restriction and blood-pressure control on the progression of chronic renal disease. Modification of diet in renal disease study group. N Engl J Med. 1994;330(13):877-84

\section{Submit your next manuscript to BioMed Central and we will help you at every step:}

- We accept pre-submission inquiries

- Our selector tool helps you to find the most relevant journal

- We provide round the clock customer support

- Convenient online submission

- Thorough peer review

- Inclusion in PubMed and all major indexing services

- Maximum visibility for your research

Submit your manuscript at www.biomedcentral.com/submit 